\title{
Researching affective atmospheres
}

\author{
C. Michels \\ Research Institute for Organizational Psychology, Research Area Cultures Institutions Markets, University of \\ St. Gallen, St. Gallen, Switzerland \\ Correspondence to: (christoph.michels@unisg.ch)
}

Received: 17 November 2014 - Revised: 21 June 2015 - Accepted: 21 August 2015 - Published: 5 October 2015

\begin{abstract}
In this contribution, I suggest activating the notion of atmospheres as a heuristic device to empirically research affects. I will argue that analysing the composition of atmospheres allows one to take into account three key dimensions of affects: their spatio-materiality, their sensuality and their (in)stability. Building on a process understanding of atmospheres, I reflect on how each of the three dimensions can be empirically researched and how they interplay in the emergence of atmospheres. I will illustrate these reflections with examples from a current research project on an artistic intervention into public spaces in Berlin.
\end{abstract}

Is there anyone who has not, at least once, walked into a room and 'felt the atmosphere'? (Brennan, 2004, p. 1)

\section{Introduction}

The opening sentence of Teresa Brennan's (2004) book The Transmission of Affect immediately evokes memories of affectively charged spaces, making the reader feel the tension, excitement or depression that can be "in the air". While the experience of atmospheres is an inherent part or our daily lives, and we are constantly affected by this fleeting and fragile phenomenon, it is extremely difficult to be analytically precise when empirically researching atmospheres. As soon as we begin to engage with empirical descriptions of the emergence of atmospheres, we're treading on slippery ground. Do we approach atmospheres by investigating the spatial and material qualities of a room and how they are modulated (as spaces seem to have an inherent atmosphere), or do we focus on how these spaces are experienced by their inhabitants (as atmospheres seem to depend on their subjective perception)? Taking this dilemma as a point of departure, in this article I follow a third option, that of conceptualising atmospheres as emerging in between their various human and non-human components. On this conceptual basis, I present possible ways to empirically research atmospheres and thus seek to make a methodological contribution to the study of affects.
My methodological reflections emerged from an empirical research project I conducted with my colleagues Laurent Marti and Manuela Ruggeri in 2011. The project followed the composition of the concert performance $X I-A$ Polytope for Iannis Xenakis, which was played on the streets and squares of Berlin by the young Berlin chamber orchestra Kaleidoskop. The concert performance lent itself particularly well to the study of atmospheres, as the musicians left the concert hall and aesthetically re-composed the spatial arrangements for playing contemporary classic music. The performance presents a series of interventions into both the atmospheres of urban spaces and the sphere of classic music making. By tracing how these atmospheric interventions become possible or remain impossible, the case allows for learning about the making of affective atmospheres and how to research them.

The paper is structured as follows. First, it explores how atmospheres have been conceptualised in philosophy and recent human geography, and how the notion of atmosphere has been related to the concept of affect. Second, I present an analytical framework derived from a conceptual understanding of affective atmospheres. This framework comes in three layers of researching affective atmospheres, illustrating each layer with examples from my empirical work on the concert performance. Finally, I reflect on my findings and conclude. 


\section{Conceptualising affective atmospheres}

In Brennan's quote cited above, the notion of atmosphere serves as a stepping stone towards understanding affects as processes that "come via an interaction with other people and an environment" (Brennan, 2004, p. 3) and thus cannot be limited to a particular person's body, but instead are understood as pre-personal and transpersonal intensities. In this article, I suggest to not step over this stone too hastily but to explore in depth how atmosphere may contribute to the researching of affects in the social sciences. To do so, I will now discuss how atmosphere has been conceptualised in different research traditions and will then outline a framework that conceptually positions my contribution.

In philosophy, atmosphere has a long history, having been addressed in the work of Bullnow, Tellenbach, Schmitz, Böhme, Griffero and Thiebaud, among others. While it would exceed this paper's scope to fully review these authors' work (for a detailed discussion, see Griffero, 2014a, Chapters 2 and 3), it can be said that most of these contributions present a (neo)phenomenological approach to atmospheres, which highlights the sensual experience of the world via perception. However, these authors have different understandings of how atmospheres are sensually perceived. As part of his "new phenomenology" Schmitz's (2009; Schmitz et al., 2011) conceptualises emotions as "atmospheres poured out spatially" (Schmitz et al., 2011, p. 247) and thereby challenges the predominant understanding of emotions as existing in or emerging from an individual's mind or soul. According to Schmitz, it is only in the experience of atmospheres via what he calls the "felt body" (Leib) that emotions become part of a person's life (Schmitz et al., 2011, p. 247). And it is the felt body (Leib) in contrast to the material body (Körper) that perceives an atmosphere; the felt body here is "understood as the extraorganic dimension and the absolute place one can only access in the first person" (Griffero, 2014b, p. 32).

This "[a]ffective involvement is an immediate, prereflexive, not yet articulated self-consciousness" (Schmitz et al., 2011, p. 245) and forms a primary and pure (Schmitz uses primitive) present that is the "original locus of identity and difference" (p. 250) and the "foundation of personhood" (p. 254). Yet the felt body is not fully disconnected from the material body as the affective involvement with emotions/atmospheres is "borne out by a surprising reliability of the gestures shown by persons moved" (p. 254). In these "vibrant attunement[s] to meaningful surroundings" (p. 244) Schmitz describes them as "diffusely meaningful situations" - the felt body undergoes a process of "encorporation" (Einleibung) of emotions/atmospheres, "more a being-perceived than a perceiving", as Griffero (2014b, p. 32) notes.

While atmospheres thus exist in "a predimensional surfaceless realm manifest to each of us in undistorted corporeal experience" (Schmitz et al., 2011, p. 245), Schmitz differentiates an atmosphere's existence from other things by de- scribing it as "half-entity", meaning that its existence may be interrupted since it depends on being experienced by someone. In this sense, atmospheres as half-entities "are only accessible to the person through their individual perspective shaped by personal experience" (p. 256). Thus, the ability to be moved by an atmosphere is conditioned by one's personal affective history. To summarise Schmitz's understanding of atmospheres they can be described as half-entities that exist in our environment, but can only be brought to life in an affectively conditioned felt body.

Griffero (2014a, b) develops Schmitz's approach by way of introducing the notion of affordance to an understanding of atmospheres as "lived spaces". Specifying Schmitz's understanding of emotions as poured out in "surfaceless space" or "space of feeling", he discusses the "specific emotional quality of a given "lived space" (Griffero, 2014a, p. 37). Distinguishing it clearly from physical space, Griffero conceptualises lived space along the concept of the felt body, to which it presents an experiential environment. The author argues that an atmospheric environment is imbued with motory and image-motory suggestions that are corporally taken up by the felt body. The felt body thus does not experience its environment by way of interpretation but by mirroring its (immanent) movements. Thus, for Griffero, "things and quasi-things [are] always already affectively connoted" (p. 46), providing atmospheres with ontologically rooted affordances.

Similar to conceptualising atmospheres in terms of affordances, Böhme (1993, 2006) suggests that one thinks of atmospheres as "in between" subject and object, but also as prior to this very distinction. His use of quasi-object addresses this ontological indeterminability of the location of atmospheres and thus differs from both Griffero's quasithing and Schmitz's half entity. For Böhme, the experience of atmospheres is this experience of co-presence, where subject and object meet via "aistheton, that is, what is perceivable" (Böhme and Farrell, 1992, p. 91). Böhme's "new aesthetics" is thus "concerned with the relation between environmental qualities and human states" (Böhme, 1993, p. 114) where the "[a]tmosphere is the common reality of the perceiver and the perceived" (p. 122). Atmospheres can thus be thought of as "a vibration (not necessarily auditory) in which the perceived and the perceiver meet and even merge isomorphically and predualistically" (Griffero, 2014a, p. 6).

In the context of human geography Anderson (2009) draws on Böhme's understanding of atmospheres as quasiobjects, yet stresses the processuality, relationality and indeterminability of the encounter between the perceiver and the perceived. Taking up the work of landscape designer Mikel Dufrenne, he argues that atmospheres are "always in the process of emerging and transforming" (p. 79). In Anderson's account of atmospheres - which resonates with what is known as non-or more-than-representational theories (NRT) (Cadman, 2009; Lorimer, 2005) - affective experience does not rely on the pre-given properties of a body or an envi- 
ronment; instead, affect pertains to the affective capacities of its components. The affective capacity of (human and nonhuman) bodies thus addresses "what a body may be able to do in any given situation, in addition to what it currently is doing and has done" (Anderson, 2014, p. 10). In actualising these capacities in lived situations - by entering into a process of mediation - bodies' capacities may change in unpredictable ways. These situations of affective mediation are therefore also processes of relational becoming or, as Deleuze and Guattari phrase it, "the nonhuman becoming of man" (quoted in Thrift, 2004, p. 63), "occurring beyond, around, and alongside the formation of subjectivity" (Anderson, 2009, p. 77).

In this sense, Anderson's taking up of phenomenological concepts is a partial one, in which the idea of atmospheres - as unfinished, pre-consciously felt and spatially composed quasi-object - is introduced in the context of a philosophy of relational and affective becoming. While the phenomenological accounts discussed above perform a clear divide between material and felt body - and, similarly, between emotional or lived space and physical space - this distinction is collapsed in the process ontology of Anderson's approach. Here the capacities of the material body and the felt body are indistinguishable preconditions and effects of affective becoming. In this process, a body's senses can be thought of as membranes that allow for resonating with a composition of vibrating matter. Accordingly, "[t]he body is no longer a transducer but rather a resonation chamber" (Massumi, 2002, p. 106). Such an understanding of affects allows for the exploration of affects (and affective atmospheres) as neither solely located in material environment nor solely in the human body, but as emerging from the resonances between its various components.

Anderson therefore distinguishes affects from feelings and emotions. In Anderson's understanding, feelings describe "proprioceptive and visceral shifts in the background habits, and postures, of a body" (Anderson, 2006, p. 736), while emotions are conceptualised as the retrospective naming or the sociolinguistic fixing of the quality of "those intimate, distinctly personal, ways of being" (Anderson, 2006, p. 737). Thus, the concept of affect in the context of NRT is a specific one that stresses the relational becoming of its components and relies on and potential changes of both a body's capacity to feel and the discursive qualifications of affects in the form of emotions. Affects neither originate in the human soul, nor are they free-floating; they "emanate from the assembling of the human bodies, discursive bodies, non-human bodies, and all the other bodies that make up everyday situations" (Anderson, 2009, p. 80).

Anderson's suggestion to conceptualise atmospheres as "spatially charged affective qualities" (p. 80) has been taken up in a growing number of contributions. In particular, human geographers (e.g. Adey et al., 2013; Bissell, 2010; Edensor, 2012; Shaw, 2014) have embraced affective atmosphere in order "to explore further the relationship between space and bodies and, specifically, how changes in the constitution of a space, whether in its characteristics or in the bodies within it, alter the affective experience of these spaces" (Shaw, 2014, p. 88). Affective atmospheres might therefore be a useful concept for those seeking to understand how the material and spatial processes of organising can be interrelated with the sensual and the affective.

However, Anderson's approach to affect in particular and more-than-representational geographies in general have recently drawn critical responses that question the promises of this research strand (e.g. Barnett, 2008; Korf, 2012; Leys, 2011; Wetherell, 2012, 2013; for a recent discussion of a feminist critique, see also Schurr, 2014). In the following, I focus on three fundamental points of criticism that relate to the concepts presented above, since a full review would exceed this paper's scope. First, Wetherell (2013, p. 233) as well as Jacobs and Nash (2003) among others argue that NRT accounts present affects as emerging between a set of undifferentiated bodies. They risk "unintentionally reinstating the unmarked, disembodied, but implicitly masculine, subject" (p. 275) and thus do not account for social power dynamics in the unfolding of affects. While it is true that NRT accounts do not assign pre-given properties to bodies, this line of criticism does not account for the different affective capacities of bodies, which make the emergence of specific forms of becoming possible or impossible. However, I would agree that much of the research published under the label of NRT tends to stress that these capacities are contingent and in a continuous flux of becoming, yet they often fail to account for how "a body's 'affective charge' is constituted through the repetition of past contexts and actions" (Anderson, 2014, p. 16) and therefore largely do not address more systematic formations of bodily capacities. From this perspective, social differences are thus not neglected but are understood as the outcome of specific affective performances that could potentially also be otherwise and thus are inherently political.

Second, it has been argued that NRT accounts present a limited understanding of affective processes that do not account for the interweaving of controlled and conscious with unconscious processes. Wetherell argues that "this is a view of the human subject as a lurching, semi-automated crash dummy, albeit one with proprioceptive sensations" (Wetherell, 2013, p. 228). Similarly, focusing on a critical reading of Massumi's work, Leys (2011) argues forcefully against what she calls an "anti-intentionalist" approach to affect in which affect is understood as an automatic response that unfolds independent from "consciousness and the mind's control" (p. 443). While the idea of an autonomous subject certainly is alien to NRT accounts, and while affects in these accounts are conceptualised as unfolding through a pre-conscious process, they nevertheless allow for an understanding of a limited agency that is distributed among the various components of an assemblage (Anderson et al., 2012), meaning that a body and its contingent capacities always do participate in and co-perform the unfolding of af- 
fective relations. As bodies are understood to enter this process in pre-conscious ways, individual agency - and, relatedly, individual responsibility - are not necessarily a given, but must be understood as achievements of specific modes of composing affective atmospheres (and their strategic and tactical effects). Put bluntly, what an individual can or cannot do always depends on the situation it becomes part of.

Third, Wetherell criticises that, in NRT accounts, affects are understood as extra-discursive realms. She argues that an NRT way of theorising "seeks to relegate the discursive almost entirely" (Wetherell, 2012, p. 56). Concerning this criticism, it needs to be acknowledged that NRT accounts have to date not been very careful with integrating the role of language in their understanding of affective becoming. Yet, in Anderson's work, we find some clues on how discourse might find a place in NRT research. For instance, Anderson and Harrison (2006, p. 335) call for developing an understanding which describes the complex relationships between theories of affect and discursive orders. In such an understanding, "discursive elements" (Anderson, 2014, p. 19, 20) could be accounted for as components of affective atmospheres. Like other components discourses, then, can be thought of as coming with specific affective capacities which allow for their resonance with other bodies and thus for their participation in the unfolding of affective atmospheres.

\section{Methodological considerations}

A further criticism of conceptualising affect in terms of more-than-representational theories regards the (im)possibility of researching affects empirically. For instance, Wetherell (2012) criticises this school of theorising affect for "block[ing] useful and pragmatic empirical work on affect" (p. 20), since NRT accounts remain vague on the question of "[h]ow can we represent that which lies beyond the scope of representation?" (Bondi et al., 2005, p. 11, quoted in Wetherell, 2012, p. 67). Acknowledging Wetherell's point that, besides some illustrative examples, there is currently very little thorough empirical research on affect in line with NRT understandings of affect, I suggest reflecting on the methodological implications that such a framework brings about, instead of dismissing it probably too hastily. As Law and Urry (2004) argue, the lack of empirical research attending to the social as fleeting, distributed, multiple, sensory, emotional and kinaesthetic (p. 403 ) is probably more an effect of the way social researchers understand and use empirical research methods than of conceptual framing. The authors therefore call for exploring possible methods of enacting social realities that are more in resonance with a world that is increasingly understood as being complex and ephemeral (p. 404). How can the sphere of empirical social research be re-composed so that it resonates with the concept of affective atmospheres?
In the following, I suggest researching affective atmospheres by exploring the processes of their composition. This includes the shaping of the components' aesthetic capacities and how these are actualised or fail to be actualised in composing affective atmospheres. Concerning the material dimensions of atmospheres, I suggest tracing the aesthetic modulation of their components in the process of aesthetic work. On a second layer, I suggest focusing on the sensual capacities of human bodies and how they are shaped by specific modes of composing. Finally, I reflect on how specific capacities of human and non-human components are reproduced in patterns and how interventions into these patterns lead to the emergence of new affective atmospheres.

My methodological reflections emerged from a research project on the preparation and performance of the concert performance XI - A Polytope for Iannis Xenakis. The piece was played by the Berlin-based music ensemble Kaleidoskop and unfolded as a 2-day musical parcourse through various public and private spaces of the city of Berlin. The performance began with a concert at the famous Berlin Philharmonic Concert Hall on the evening of the first day. The evening ended with some musicians leaving the concert hall and continuing their performances on nearby streets and squares. On the second concert day, the ensemble did socalled guerrilla concerts at various iconic public sites in the city, which culminated at the end of day 2 in a "polytopic concert performance". During this third part of the performance, the musicians split up and played at 15 different remote locations, transmitting their music via mobile devices to a derelict field in the middle of the city. On the field, 15 cars received the signals and amplified the music with their stereo systems, while moving in slow choreography across the field. The audience was invited to move between the cars and to thus explore the concert performance in fragmented and constantly changing ways. ${ }^{1}$

The research project organised the material in resonance with the question of how (affective) atmospheres are composed and re-composed in the preparations for and performance of the concert. In the process of our research, we experimented with various ways of gathering and analysing empirical material. The examples presented in the following do not present the entire research case and its findings, but seek to provide some insights into how the material was gathered and organised in resonance with the concept of affective atmospheres. The following part is organised in three methodological sections, each presenting a different layer of affective empirical research through atmospheres: the tracing of material modulations, the exploration of sensual capacities and the (de)stabilisation of affective atmospheres. Each section first presents a conceptual and methodological reflection, which is then related to examples from the research project.

\footnotetext{
${ }^{1}$ To watch the trailer to the concert documentation, go to https: //www.youtube.com/watch?v4IFKgMyMPvU.
} 


\subsection{Tracing the material modulation of atmospheres}

As a first empirical layer to researching affective atmospheres, I suggest focusing on the processes that modulate the affective capacities of material components. These processes comprise the professional work of designers and artists as much as everyday practices such as lighting a candle, applying make-up or rearranging furniture in a room. Every modulation explores and actualises specific affective capacities of one or several objects. Böhme (1993, p. 123) has described these processes with the term "aesthetic work" as " 'making' atmospheres through work on an object". Aesthetic work can be described as a process through which material components are selected and shaped so as to make them resonate with the affective capacities of an (everyday) artist. The process of aesthetic work therefore always emerges in resonance with the body of an author (individual or collective). When an architect, a musician or any other human body (co)modulates an atmosphere, the material environment is carefully "tuned" to his or her body and its sensual capacities.

Since not all available components have the capacities of resonating equally well with an author's body, aesthetic work is a process of more or less systematic selecting, testing and shaping of material components. In the following, I present the preparation of the concert as an example for how an atmosphere is materially modulated through aesthetic work. The account describes the material modulation of the concert performance in resonance with the artists' bodies and their sensual capacities. Accounting for the processes of aesthetic work, we proceeded ethnographically with a particular focus on the fine attunements of the sensual (Crang, 2003; Paterson, 2009). More concretely, this meant attending to the aesthetic and compositional practices through which the concert was modulated so that it started to feel "right" to the artists. One way to "get into the skin" of an artist and to know her or his sensations was by taking on the role of a "sensory apprentice" (Pink, 2009). In this role, we followed and sought to understand the artist's sense-making by way of participant observation and (narrative) interviews, sometimes co-evoked by the presence of specific objects or the exploration of specific sites. Joining the process of aesthetic work, eating, talking, sitting, cooking and walking with our research partners, we gradually learnt about their experiential worlds.

For instance, we followed the stage designer's work for several days. The stage designer, who often collaborates with the ensemble, was in charge of the design of the second part of the concert, the so-called guerrilla concerts. Her work consisted in inventing a solution for how the concert performance could unfold in the city's public streets and squares. In our ethnographic study, we joined and supported her whenever possible: in her studio, on the streets, in the workshop, where a portable sculpture was crafted, or when buying material. In each site, we used audio-visual recordings to document the work progress. However, we did not remain silent observers, but initiated conversations whenever suitable, asking her about her work and how and why she worked the ways she did. These conversations were sometimes short informal exchanges and sometimes took the form of more formal interviews.

One day, we went with the artist and her assistant to explore various potential sites for the guerrilla concerts. After exploring each site for a few minutes, we conducted short onsite interviews with the artists, asking how they experienced the location and what ideas they had. It became clear to us how the various sites resonated with the artists' imagination, how they became part of the composition of the guerilla parcourse, or how they left the artists unaffected. In an on-site interview on Alexanderplatz, it became most apparent how the modulation of the parcourse depended on the artists' sensual capacities and how these sometimes differed between the stage designer and her colleague:

Researcher: How does Alexanderplatz fit the concept of the guerilla parcourse? Has Alexanderplatz always been central to it, or somehow important to it?

Aliénor [the stage designer]: I have always seen Alexanderplatz as a key location. But this differs. Everybody who lives in Berlin has a different perception. And Korneel [her colleague] does not see it as a centre, right?

Korneel: No, I am one of those who is disappointed by Alexanderplatz, because it has a certain reputation, a name, in literature and film history. And then you get here and you see the Galleria Kaufhof [a shopping centre] and C\&A and this ugly square, that actually is not a square; there is no shade and so on. I have never seen it as a centre of the city, unlike the other side of the station. There you have more qualities. But there we have a controversy. It's a controversial place, as you said, everyone has a different idea of it. I would find it interesting if it became part of the parcourse, especially because then something would happen here besides the Easter market. But you have always seen it as a central location. I remember, half a year ago [...] your installation with the cameras also took place here.

Aliénor: Yes, in the history of the project, Alexanderplatz has always been part of it. But I am not obsessed by it. [...]

Korneel: In my imagination of the parcourse, Alexanderplatz keeps getting in and out and in and out.

This interview excerpt shows how site selection is a process that resonates with the sensual capacities of the two artists, both equipped with different capacities of resonating 
with Alexanderplatz. While the stage designer has a clear fascination for the square and has a history of using it as a performance site, her colleague has very different feelings about it, finding the place disappointing. As the entire parcourse consisted of five locations, its modulation unfolded in iterative work cycles in which the parcourse had to continuously be adjusted to both the artists' sensual capacities and the sites' capacities to resonate with them.

\subsection{Exploring the sensual capacities of bodies}

While the previous section focused on material modulations of atmospheres and how they can be researched, in this section, I discuss how researchers can attend to sensing bodies and how they are affected by materially modulated environments. To better understand how bodies succeed or fail in resonating with specific material modulations, I draw on Reckwitz's (2012, p. 254) and Löw's (2001, p. 209) suggestions to think a body's capacity through the Bourdieuinspired notions of habitus and habitualisation. While habitus refers to an attitude of the body, a way of resonating unconsciously with its environments, habitualisation describes a process through which a body's affective capacity is formed or (re)modulated. Habitualisation can thus be seen as the counterpart of what I have before described as aesthetic work; it describes the formation of a human body's affective capacities. In this sense, habitus does not represent any fixed (social) structure but, rather, addresses how affective capacities are shaped - and to a certain degree stabilised - in human bodies. And as Wise (2010), drawing on Bourdieu, argues, "[i]t is precisely because of their embodied nature that habitus and hexis have the capacity to induce in us affective responses to inter-subjective encounters with those around us and to interactions with our environment" (p. 922).

In our research, the (in)capacity of habitualised bodies to resonate with the concert performance became clear in the reactions of the passersby. Some simply "escaped" the performance, while others stopped and watched the performance with admiration; many started recording the concert on their smartphones. Yet others expressed anger and frustration with the performance by yelling insults at the musicians. In the following, I present an auto-ethnographic field note (Spry, 2011), reflecting my own (in)capacity of resonating with the performance:

It is late on Saturday night, dark, windy and rainy. My shoes and socks are soaked and I am tired of the past $24 \mathrm{~h}$ of observing and filming the XI concert performance. Standing in the middle of a derelict field (the Gleisdreieck) in the centre of Berlin, I am operating a camera placed on a tripod in front of me. It's a bit frustrating, as it is quite difficult to capture the cars, which pass in the distance. Once in a while, when a car comes closer to the camera, I can perceive some of the "music" em- anating from the car. But I am unsure if this actually classifies as music, since the sound is very distorted, fragmented and unpleasant, not only to me but also to the drivers, many of which have plugged their ears. Most of the audience has gone home; only a few brave spectators (I think most of them are parents or friends of the musicians) remain on the field, trying to protect themselves with umbrellas, which continuously collapse in the wind.

After an hour or so, I head towards the "base": an old truck parked on the periphery of the field. I need shelter from the weather and long for some warmth. On my way to the truck I meet Volker, the ensemble's general manager. He is very exited and asks me if I had seen and filmed the air from the exhausts reflecting the cars' headlights. It is beautiful, he says. I am unsure if I really understand what he is talking about and continue en route to the truck. After having dried in rudimentary way, and eaten some chocolate, I peek through one of the wet windows onto the field. Three or four cars are slowly heading towards the truck. The headlights dramatically shed light on the pouring rain and the vapour that rises from the cars. There is the quiet sound of various distorted string instruments emanating from the scene, and for a moment I forget about my cold feet, my hungry stomach and my tired body, and am captured by the beauty of the moment. For a split second, I think about getting the camera ready to capture this experience. But I decide not to, because I thought that fiddling with the camera would ruin the experience.

The field note presents how a body's capacity can depend on minor modulations in a composition. Upon entering the truck and putting away the camera, and perhaps also due to the hint of the general director, I saw the situation in an entirely different light. Its beauty emerged as the atmosphere was re-modulated so as to resonate with my body's sensual capacities. Reflecting on the situation, these capacities depended on a very basic need for comfort. Being in the rain with a frustrating task to film was simply a situation I was not used to, in contrast to the filmmaker in our team, who joined me a bit later in the truck. She fully resonated with the concert performance, radiating an excitement that surprised me. In a short conversation with her, it became clear that she in fact had made beautiful recordings of the scene, and this composition of beautiful takes, the concert and her body as filmmaker excited her. Perhaps, owing to her training as filmmaker, she had the capacity to relate to the situation in a way that my body was not capable of. It was only after I had put away the camera that I managed to really tune in to the concert's atmosphere. 


\subsection{Accounting for the (in)stability of atmospheres}

As the final and perhaps most challenging part of an empirical approach to atmospheres and their making, I address the question how habitualised bodies and materially modulated environments are stabilised, how they can fall apart and how they sometimes change and allow for the emergence of new atmospheric compositions. This third layer of empirical research refers to the phenomenon that, although no atmosphere exactly resembles another, and although atmospheres are multiple in themselves, we can trace similarities and patterns in their compositions. Exploring the (de)stabilisation of atmospheres implies exploring the mutual interplay between material modulations and sensing bodies. How do they achieve a perpetuation of their resonation and how are these eventually put into crisis?

To understand how atmospheric changes come about, one must ask how new affective capacities of components are explored and actualised. I have argued that the sensual capacities of material environments emerge through (re)modulations and that bodies' sensual capacities are formed by processes of (de)habitualisation. These two processes depend on and can mutually stabilise or destabilise each other. Habitualised bodies (re)produce material modulations through processes of aesthetic work and, vice versa, material modulations perpetuate or challenge the formation of habitualised bodies.

In this sense, we can think of modes of atmosphere-making that reproduce or challenge specific patterns of atmospheric compositions. These modes can be thought of in line with what Gammerl (2012) refers to as "spatially defined emotional styles" (p. 164). The classic concert performance, for instance, has been composed in fairly consistent ways across the world for the past 100 years, reproducing specific forms of modulating the concert hall and the music played therein. Likewise, the audience, the musicians and all the other sensing human bodies resonate with the performance of the concert (sphere) in a more or less consistent way (Johnson, 1994). Yet it could also be argued that the compositions of concert performances have changed over the years, with every concert presenting a slightly different set of components and sometimes new elements, and different bodies have challenged established ways of composing the concert sphere. New modes of composing concerts emerge as different bodies, locations, buildings, technologies, etc. affect and are affected by the concert sphere. Hennion (2001) for instance discusses how the availability of recordings have changed the experience of concert performances.

Researchers of atmospheres may therefore also attend to patterns in the composition of atmospheres and how they are reproduced or changed. Describing patterns in the composition of atmospheres requires a researcher to "zoom out" and to describe similar compositions of affective atmospheres at other sites. Furthermore, researchers can follow how habitualised bodies and practices of aesthetic work travel from site to site. Tracing the lives and work trajectories of both the participating artists and the audience may reveal how practices of modulating and ways of sensing atmospheres are reproduced and challenged in the composition of an atmosphere.

In the case of our research project, we were able to identify various patterns that were re-produced and re-composed in the modulation of the concert performance. The various fragments of patterns comprised practices and components from the concert sphere as much as elements and practices that are usually not part of performing classic music, such as ninja costumes, a portable structure, amplifiers, and certainly the selection of public urban sites. In the preparations for and performance of the concert, these elements, their histories and specific logics all became part of the composition. The concert performance emerged through a collaborative process that include the work of several artists from other disciplines (a composer, a stage designer, a choreographer, a tailor, a filmmaker, a team of parkour runners) and our research team, bringing together a number of different modes of aesthetic work. Their heterogeneous re-composition in the XI concert performance destabilised each of these modes and created a space for new resonances and new atmospheric performances.

However, this fragmentary way of composing a concert performance itself reproduces a compositional pattern that has been established in experimental music making and what in German is known as Neue Musik. Looking at the ensemble's history and professional environment, it became clear that the experiential collaboration with other disciplines, new spaces and unconventional components represents a working mode that has been developed since the 1920s. It is probably most manifest at the Donaueschinger Musiktage, an annual festival for contemporary classic music, where experimental forms of music making shape the event's atmosphere.

\section{Reflection and conclusion: the performativity of empirical research on atmospheres}

Having presented some ideas on how the concept of atmospheres can serve as a heuristic handle for researching affects, I conclude with a reflection on the performativity of researching atmospheres in this way. From a performative or more-than-representational perspective, the methods of gathering and analysing empirical material are themselves performative (Law, 2004). Concerning the study of atmospheres, I suggest reflecting on three aspects of the performativity of this research approach.

The first reflection concerns the question what we gain by re-composing the social in terms of affective atmospheres. By attending to the composition of atmospheres through the three empirical layers presented above, we make visible the ways in which the social is affectively composed. Concerning atmospheres, Böhme (1993) has defined "the task of making [the] broad range of aesthetic reality transparent and 
articulable" (p. 125). By developing this perspective, social research can contribute to an understanding of the politics of atmospheric compositions, particularly with respect to the practices of aesthetic work and the habitualisation of bodies. In relation to the research project, we can for instance ask how specific compositions become possible while others remained impossible.

The second reflection asks how the organisation of empirical social research itself can be understood as an atmospheric composition and how these compositions are reproduced or changed. Framing social research in terms of atmospheres makes visible how research itself depends on and emerges through specific affective compositions. For instance, a research project can be understood as a composition of specific tools, buildings, habitualised bodies, practices, vocabularies, etc. Doing research is a way of reproducing and occasionally re-inventing the established spheres of social research, for instance by introducing new terms, methods or bodies into its composition.

I argue that interdisciplinary research is one possible way to irritate a discipline's affective dynamics and can lead to the emergence of new research compositions. This can unfold by introducing concepts from other disciplines (e.g. the notion of atmosphere, which has a history in the arts and philosophy) or by experimenting with other methods (e.g. videographic work). Collaborating within an interdisciplinary team yields great potential, but also the danger of irresolvable tensions. For instance, in our project, we collaborated with a professional filmmaker who helped us to gather our empirical material in a way that actualised the visual research's aesthetic potential, but who also brought a logic of scripting to the field, which created tensions with our more inductive research approach.

The third reflection concerns the distinction of the three layers of empirical research on atmospheres, as presented above. Both the conceptual discussions and the empirical illustrations of theses layers have shown how firmly these three layers are interwoven. By heuristically decomposing atmospheres into three distinct layers, I sought to make empirically approachable the various processes that lead affective atmospheres to emerge or prevent them from being actualised. The distinction made resonant the concept of atmosphere with fairly established research methods of the social sciences, such as (auto-)ethnography, interviews and visual research methods. The concept of atmospheres, which is otherwise empirically difficult to approach in this way, became empirically more accessible - or so I hope.

However, decomposing atmospheres along these lines may not resonate with other ways of conceptualising and researching affective atmospheres. In this sense, I conclude with an invitation to further explore processes of researching affects via the notion of atmospheres. Here, I presented some ideas of how empirical work on atmospheres can be done. However, it is important to read my contribution not as a guideline on how to research atmospheres, but as one potential way - among others - of re-modulating the methodological landscape of the social sciences.

Edited by: B. Korf

Reviewed by: two anonymous referees

\section{References}

Adey, P., Brayer, L., Masson, D., Murphy, P., Simpson, P., and Tixier, N.: "Pour votre tranquillité": Ambiance, atmosphere, and surveillance, Geoforum, 49, 299-309, doi:10.1016/j.geoforum.2013.04.028, 2013.

Anderson, B.: Becoming and being hopeful: towards a theory of affect, Environ. Plan. Soc. Space, 24, 733-752, doi:10.1068/d393t, 2006.

Anderson, B.: Affective atmospheres, Emot. Space Soc., 2, 77-81, doi:10.1016/j.emospa.2009.08.005, 2009.

Anderson, B.: Encountering affect: capacities, apparatuses, conditions, Ashgate, Farnham, 2014.

Anderson, B. and Harrison, P.: Questioning affect and emotion, Area, 38, 333-335, doi:10.1111/j.1475-4762.2006.00699.x, 2006.

Anderson, B., Kearnes, M., McFarlane, C., and Swanton, D.: On assemblages and geography, Dialogues Hum. Geogr., 2, 171-189, 2012.

Barnett, C.:Political affects in public space: normative blind-spots in non-representational ontologies, Trans. Inst. Br. Geogr., 33, 186-200, doi:10.1111/j.1475-5661.2008.00298.x, 2008.

Bissell, D.: Passenger mobilities: affective atmospheres and the sociality of public transport, Environ. Plan. Soc. Space, 28, 270289, doi:10.1068/d3909, 2010.

Böhme, G.: Atmosphere as the fundamental concept of a new aesthetics, Thesis Elev., 36, 113-126, 1993.

Böhme, G.: Architektur und Atmosphäre, W. Fink, München, 2006.

Böhme, G. and Farrell, J.: An Aesthetic Theory of Nature: an Interim Report, Thesis Elev., 32, 90-102, doi:10.1177/072551369203200107, 1992.

Brennan, T.: The Transmission of Affect, Cornell University Press, Ithaca, 2004.

Cadman, L.: Nonrepresentational Theory/Nonrepresentational Geographies, in: International Encyclopedia of Human Geography: A 12-Volume Set, edited by: Kitchin, R. and Thrift, N., 1-8, Elsevier Science, Amsterdam, 2009.

Crang, M.: Qualitative methods: touchy, feely, look-see?, Prog. Hum. Geogr., 27, 494-504, doi:10.1191/0309132503ph445pr, 2003.

Edensor, T.: Illuminated atmospheres: anticipating and reproducing the flow of affective experience in Blackpool, Environ. Plan. Soc. Space, 30, 1103-1122, doi:10.1068/d12211, 2012.

Gammerl, B.: Emotional styles - concepts and challenges, Rethink. Hist., 16, 161-175, doi:10.1080/13642529.2012.681189, 2012.

Griffero, P. T.: Atmospheres: Aesthetics of Emotional Spaces, Ashgate Publishing, Ltd., 2014a.

Griffero, T.: Atmospheres and Lived Space, Stud. Phaenomenologica, 14, 29-51, 2014b.

Hennion, A.: Music Lovers. Taste as Performance, Theory Cult. Soc., 18, 1-22, 2001.

Jacobs, J. and Nash, C.: Too little, too much: Cultural feminist geographies, Gend. Place Cult., 10, 265-279, 2003. 
Johnson, J. H.: Listening in Paris: A Cultural History, University of California Press, Berkeley, 1994.

Korf, B.: Geographie des Denkens, Geogr. Z., 100, 146-163, 2012.

Law, J.: After Method: Mess in social science research, Routledge, London, 2004.

Law, J. and Urry, J.: Enacting the social, Econ. Soc., 33, 390-410, 2004.

Leys, R.: The turn to affect: A critique, Crit. Inq., 37, 434-472, 2011.

Lorimer, H.: Cultural geography: the business of being "more-thanrepresentational,” Prog. Hum. Geogr., 29, 83-94, 2005.

Löw, M.: Raumsoziologie, Suhrkamp, Frankfurt a. M., 2001.

Massumi, B.: Parables for the Virtual: Movement, Affect, Sensation, Duke University Press, Durham, 2002.

Paterson, M.: Haptic geographies: ethnography, haptic knowledges and sensuous dispositions, Prog. Hum. Geogr., 33, 766-788, doi:10.1177/0309132509103155, 2009.

Pink, S.: Doing Sensory Ethnography, Sage, London, 2009.

Reckwitz, A.: Affective spaces: a praxeological outlook, Rethink. Hist., 16, 241-258, doi:10.1080/13642529.2012.681193, 2012.

Schmitz, H.: Der Leib, der Raum und die Gefühle, 2. ed., Edition Sirius, Bielefeld, 2009. f
Schmitz, H., Müllan, R. O., and Slaby, J.: Emotions outside the box - the new phenomenology of feeling and corporeality, Phenomenol. Cogn. Sci., 10, 241-259, doi:10.1007/s11097-0119195-1, 2011.

Schurr, C.: Emotions, affects and more-than-representational geographies, Geogr. Z., 102, 148-161, 2014.

Shaw, R.: Beyond night-time economy: Affective atmospheres of the urban night, Geoforum, 51, 87-95, doi:10.1016/j.geoforum.2013.10.005, 2014.

Spry, T.: Performative autoethnography: Critical embodiments and possibilities, in: Handbook of qualitative research, edited by: Denzin, N. K. and Lincoln, Y. S., 497-512, SAGE, Thousand Oaks, CA, 2011.

Thrift, N.: Intensities of Feeling: Towards a Spatial Politics of Affect, Geogr. Ann. Ser. B Hum. Geogr., 86, 57-78, 2004.

Wetherell, M.: Affect and Emotion: A New Social Science Understanding, Sage, London, 2012.

Wetherell, M.: Feeling rules, atmospheres and affective practice: Some reflections on the analysis of emotional episodes, in: Privilege, Agency and Affect: Understanding the Production and Effects of Action, edited by: Maxwell, C. and Aggleton, P., 221239, Palgrave Macmillan, London, 2013.

Wise, A.: Sensuous Multiculturalism: Emotional Landscapes of Inter-Ethnic Living in Australian Suburbia, J. Ethn. Migr. Stud., 36, 917-937, doi:10.1080/13691831003643355, 2010. 